\title{
Spliceosome disassembly catalyzed by Prp43 and its associated components Ntr1 and Ntr2
}

\author{
Rong-Tzong Tsai, ${ }^{1,4}$ Ru-Huei Fu, ${ }^{1,4}$ Fu-Lung Yeh, ${ }^{1,4}$ Chi-Kang Tseng, ${ }^{1,3}$ Yu-Chieh Lin, ${ }^{1,2}$ \\ Yu-hsin Huang, ${ }^{1}$ and Soo-Chen Cheng ${ }^{1,2,3,5}$ \\ ${ }^{1}$ Institute of Molecular Biology, and ${ }^{2}$ Taiwan International Graduate Program, Molecular and Cellular Biology, Academia \\ Sinica, Nankang, Taipei, Taiwan 115, Republic of China; ${ }^{3}$ Institute of Microbiology and Immunology, National Yang-Ming \\ University, Shih-Pai, Taipei, Taiwan 112, Republic of China
}

Two novel yeast splicing factors required for spliceosome disassembly have been identified. Ntr1 and Ntr2 (NineTeen complex-Related proteins) were identified for their weak association with components of the Prp19-associated complex. Unlike other Prp19-associated components, these two proteins were primarily associated with the intron-containing spliceosome during the splicing reaction. Extracts depleted of Ntr1 or Ntr2 exhibited full splicing activity, but accumulated large amounts of lariat-intron in the spliceosome after splicing, indicating that the normal function of the Prp19-associated complex in spliceosome activation was not affected, but spliceosome disassembly was hindered. Immunoprecipitation analysis revealed that Ntr1 and Ntr2 formed a stable complex with DExD/H-box RNA helicase Prp43 in the splicing extract. Ntr1 interacted with Prp43 through the N-terminal G-patch domain, with Ntr2 through a middle region, and with itself through the carboxyl half of the protein. The affinity-purified Ntr1-Ntr2-Prp43 complex could catalyze disassembly of the spliceosome in an ATP-dependent manner, separating U2, U5, U6, NTC (NineTeen Complex), and lariat-intron. This is the first demonstration of physical disassembly of the spliceosome, catalyzed by a complex containing a DExD/H-box RNA helicase and two accessory factors, which might function in targeting the helicase to the correct substrate.

[Keywords: Spliceosome disassembly; NTR complex; Prp43; Ntr1; Ntr2]

Supplemental material is available at http://www.genesdev.org.

Received September 21, 2005; revised version accepted October 28, 2005.

Introns are removed from precursor messenger RNA (pre-mRNA) via a two-step transesterification reaction catalyzed by a large ribonucleoprotein particle called the spliceosome (Brody and Abelson 1985; Frendewey and Keller 1985; Grabowski et al. 1985). The spliceosome consists of U1, U2, U4/U6, and U5 small nuclear ribonucleoprotein particles (snRNPs) as well as non-snRNP protein factors that bind to the pre-mRNA in a sequential manner (for reviews, see Burge et al. 1999; Brow 2002). Following binding of all four snRNPs, the spliceosome undergoes a large structural rearrangement, releasing U1 and U4 and forming new base pairings between $\mathrm{U} 2$ and U6 and between U6 and pre-mRNA. This leads to the activation of the spliceosome, on which catalytic reactions can take place.

During spliceosome activation, a protein complex as-

\footnotetext{
${ }^{4}$ These authors contributed equally to this work.

${ }^{5}$ Corresponding author.

E-MAIL mbscc@ccvax.sinica.edu.tw; FAX 886-2-27883296.

Article and publication are at http://www.genesdev.org/cgi/doi/10.1101/ gad.1377405.
}

sociated with Prp19 (named NTC for NineTeen Complex) is added to the spliceosome (Tarn et al. 1993b, 1994). NTC is not required for dissociation of U1 or U4, but is required for stabilization of U5 and U6 on the spliceosome after U4 is released (Chan et al. 2003). UVcross-linking analysis revealed that interactions between U5 and U6 with pre-mRNA change from a dynamic state to a highly specific state during spliceosome activation (Chan et al. 2003; Chan and Cheng 2005). Furthermore, U6 snRNP is remodeled such that Lsm proteins are destabilized from U6 snRNA to expose the 3 '-terminal U-tract for more interactions with the intron. These events, which establish stable association of U5 and U6 with the spliceosome, are dependent on the presence of NTC, indicating that NTC plays a role in mediating such structural rearrangements.

Eight proteins have been identified to be components of NTC by a combination of biochemical and genetic methods. They include Syf1/Ntc90, Cef1/Ntc85, Clf1/ Ntc77, and Prp19 (Tsai et al. 1999; Chen et al. 2001, 2002), encoded by essential genes, and Syf2/Ntc31, Isy1/ Ntc30, Snt309/Ntc25, and Ntc20 /Chen et al. 1998, 
2001, 2002), encoded by genes not essential for cellular growth. These proteins are associated with the spliceosome at the same time during spliceosome assembly in a step after the dissociation of U4, suggesting that they might function as an integral complex. Interestingly, all of these proteins were also found in the yeast pentasnRNP complex, which is proposed to be a functional particle of the preassembled spliceosome capable of splicing added pre-mRNA (Stevens et al. 2002).

Homologs of several NTC components, Prp19, Ntc90, Ntc85, Ntc77, Ntc30, and Ntc25, are also found in the $35 \mathrm{~S}$ complex identified in mammalian splicing extracts by gradient sedimentation (Makarov et al. 2002). The 35S complex contains U5 snRNP with an incomplete set of protein components and a subset of proteins found in the $45 \mathrm{~S}$ activated spliceosome. It has been proposed that this complex might represent a disassembly intermediate generated from the activated spliceosome post-splicing reaction (Makarov et al. 2002).

Disassembly of the spliceosome after completion of the splicing reaction is necessary for recycling of splicing factors to promote efficient splicing. The molecular mechanism of the disassembly has not been extensively studied. The yeast Prp22 protein, a DExD/H-box RNA helicase, is required for the dissociation of the mature message from the spliceosome (Company et al. 1991), but also plays a role in the second catalytic step (Schwer and Gross 1998). Another protein of the DExD/H-box family Prp43 has been shown to be involved in spliceosome disassembly in the release of lariat-intron (Arenas and Abelson 1997; Martin et al. 2002). Both Prp22 and Prp43 confer RNA-dependent ATPase activities, which are required for the release of $\mathrm{mRNA}$ and lariat-intron, respectively (Schwer and Gross 1998; Martin et al. 2002). Nevertheless, the mechanistic details of the disassembly process remain unclear.

The availability of genome sequences has facilitated global studies of gene functions. Several yeast proteomic databases provide valuable information for analyzing constituents of complex assemblies involved in various biological pathways (Zhou et al. 2002; Hazbun et al. 2003; Krogan et al. 2004). Two yeast ORFs, YLR424w and YKR022c, of unknown function are found to associate with proteins that include five NTC components and other known splicing factors (Hazbun et al. 2003). On testing whether these two gene products were components of NTC, we found that these two proteins, being only weakly associated with NTC, were not required for either the assembly of the spliceosome or catalytic reactions, but were required for disassembly of the spliceosome after the splicing reaction is complete. Immunoprecipitation analysis revealed that these two proteins formed a stable complex with Prp43. The affinity-purified complex could catalyze disassembly of the spliceosome in an ATP-dependent manner, separating U2, U5, U6, NTC, and lariat-intron. Our results not only demonstrated physical disassembly of the spliceosome, but also showed essential function of Ntr1 and Ntr2 as accessory factors of Prp43 in catalyzing spliceosome disassembly.

\section{Results \\ Coprecipitation of Ntr1 and Ntr2 with NTC components}

Three uncharacterized ORFs were suggested to be splicing factors in a recent study of yeast proteomes (Hazbun et al. 2003). Two of these proteins, YLR424w and YKR022c, were purified together with five identified NTC components as well as several other splicing factors. To verify whether these two proteins are components of NTC, YLR424w and YKR022c were tagged with the HA-epitope for immunoprecipitation with the antiHA antibody, and proteins coprecipitated with Prp19 and with YLR424w or YKR022c were compared. Extracts prepared from PRP19-HA, YLR424w-HA, YKR022c-HA, and nontagged strains were precipitated with the antiHA antibody followed by Western blotting as shown in Figure 1A. Due to differences in the accessibility of the HA-epitope on each protein, different amounts of the antibody were used for precipitation of different extracts as indicated in the legend to Figure 1. Precipitated proteins were first probed with the anti-HA antibody to reveal Prp19-HA, YLR424w-HA, and YKR022c-HA. The amounts of precipitated materials loaded on the gel were adjusted accordingly to contain approximately the same amount of HA-tagged proteins in each lane. Association of NTC components with Prp19-HA, YLR424w-HA, and YKR022c-HA was compared by Western blotting probed with antibodies against NTC components. Figure 1A shows that all the identified NTC components were coprecipitated with YLR424w and YKR022c, but at much lower levels than those coprecipitated with Prp19, indicating that both YLR424w and YKR022c were either weakly associated with NTC or only a small fraction was associated with NTC. YLR424w and YKR022c were unlikely true NTC components, and were therefore named Ntr1 and Ntr2, respectively, for NTC-related proteins. The protein sequences of Ntr1 and Ntr2 are shown in Figure 1B.

\section{Ntr1 and Ntr2 are associated with the intron-containing spliceosome}

Eight proteins have previously been identified to be components of NTC (Chen et al. 1998, 2001, 2002; Tsai et al. 1999). All of these proteins bind to the spliceosome at the same time during spliceosome assembly in a step after dissociation of $\mathrm{U} 4$ but prior to catalytic reactions. To determine whether Ntr1 and Ntr2 bind to the spliceosome in a similar way to NTC components, the spliceosomes formed in HA-tagged Ntr1 or Ntr2 extracts at various ATP concentrations were immunoprecipitated with anti-HA and anti-Ntc20 antibodies as shown in Figure 2. In Ntr1-HA extracts, although no splicing products were detected at $0.1 \mathrm{mM}$ ATP (Fig. 2A, lane 1), a small amount of pre-mRNA was precipitated by the antiNtc20 antibody (Fig. 2A, lane 2), indicating formation of a small amount of the active spliceosome under this condition. Nevertheless, the anti-HA antibody did not precipitate any pre-mRNA. At 0.5 or $2 \mathrm{mM} \mathrm{ATP}$, large 
A

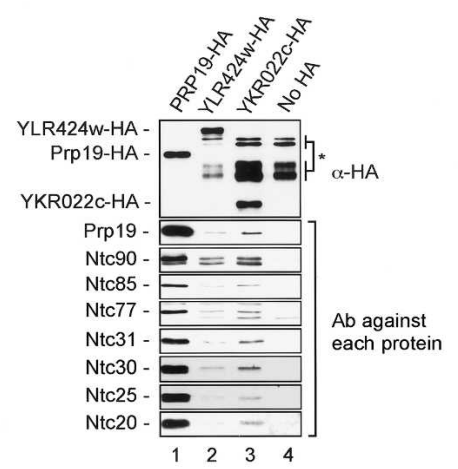

B

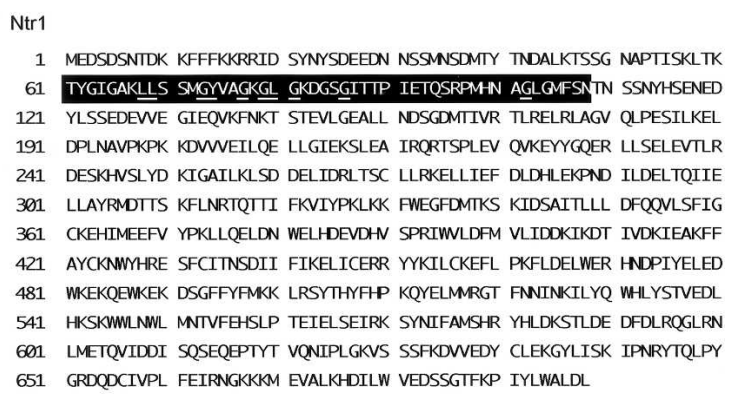

Ntr2

1 MAIKKPNNIR LPSGSPEEVG IDGSAHKPMQ QIKPLVSNDS EDDDNDICVL OPIKFKKVPK 61 RDITFDGEQA IKEDNSHYED LYHSKKNTNA STRNKDDLLI LNMEDLMEGN HHLLSDSSEA 121 GSSSEGEHIS SIPTRGEIAK LKAOKSLSRR KISESDVTTE RDWKLLDSE DKREIMEIIR 181 LNGGLKRNNE KEITNFSDDE MDGFODEMLA LTDNOTATOK DSKRKIIEKA INEVPYRTNE 241 ENETQLLSKG NINKSNEKII TPLPVLFPDD DESGNSIERI NEMVSKICLQ RKKVEMRLQA 301. LEKTKIDLEK SKASLINKLI GN

Figure 1. YLR424w and YKR022c as NTC-related proteins Ntr1 and Ntr2. (A) Extracts prepared from PRP19-HA (lane 1), YLR424w-HA (lane 2), YKR022c-HA (lane 3), and nontagged (lane 4) strains were immunoprecipitated with an anti-HA antibody followed by Western blotting. For each $200 \mu \mathrm{L}$ of extract, $10 \mu \mathrm{L}, 40 \mu \mathrm{L}, 100 \mu \mathrm{L}$, and $100 \mu \mathrm{L}$ of the monoclonal anti-HA antibody were used for immunoprecipitation of PRP19-HA, YLR424w-HA, YKR022c-HA, and nontagged extracts, respectively. Precipitates were first probed with anti-HA antibody to reveal Prp19-HA, YLR424w-HA, and YKR022c-HA in each sample. The amount of precipitated samples loaded on the gel was adjusted accordingly so that each lane contained approximately the same molar amounts of HA-tagged proteins. (B) Protein sequence of Ntr1 and Ntr2. The G-patch domain of Ntr1 is highlighted. Conserved residues are underlined.

amounts of pre-mRNA, splicing intermediates, and products were precipitated by the anti-Ntc20 antibody (Fig. $2 \mathrm{~A}$, lanes 6,10$)$, but only the lariat-intron was precipitated by the anti-HA antibody (Fig. 2A, lanes 8,12). Similar results were obtained with Ntr2-HA extracts (Fig. 2B), except that a trace amount of splicing activity was detected in this extract at $0.1 \mathrm{mM}$ of ATP. These results suggest that Ntr1 and Ntr2 behave differently from NTC in their binding to the spliceosome during spliceosome assembly in that they are present primarily on the intron-containing spliceosome.

To rule out the possibility that failure in coprecipitating pre-mRNA or splicing intermediates with Ntrl or Ntr2 was due to inaccessibility of the HA-epitope to the antibody during early steps of spliceosome assembly, proteins present on the total spliceosome and the active spliceosome were examined by precipitation with streptavidin agarose of spliceosomes formed on biotinylated wild-type and Ac/Cla actin pre-mRNA. The Ac/Cla premRNA is actin-sequence-truncated beyond the branch point and thus, although unable to undergo catalytic reactions, allows formation of the active spliceosome and binding of NTC (Cheng 1994). As shown in Figure 2C, Ntr1 and Ntr2 were found on the spliceosome formed with wild-type pre-mRNA (lane 2), but only present in trace amounts with Ac/Cla pre-mRNA (lane 4), in contrast to NTC components, Prp19, Ntc85, and Ntc30, which were effectively associated with both pre-mRNA. It is speculated that binding of low levels of Ntrl and Ntr2 to Ac/Cla pre-mRNA might be through their association with NTC. Nevertheless, this result is consistent with that of the immunoprecipitation experiment, in which Ntr1 or Ntr2 coprecipitated predominantly lariat-intron, and suggests that these two proteins become associated with the spliceosome primarily during or after catalytic steps.

\section{Ntr1 and Ntr2 are required for the release} of lariat-intron from the spliceosome

To examine the function of Ntr1 and Ntr2 in the splicing reaction, Ntr1 and Ntr2 were individually depleted from Ntr1-HA or Ntr2-HA extracts, with the anti-HA antibody for splicing assays. As shown in Figure 3A, while depletion of Prp19 abolished the splicing activity (lane 2), depletion of Ntr1 or Ntr2 resulted in accumulation of lariat-intron after splicing (lanes 4,6). This indicates that neither Ntr1 nor Ntr2 was essential for the splicing reaction, but both proteins were required either for disassembly of the spliceosome in release of either mature mRNA or lariat-intron, or required for the degradation of lariat-intron RNA.

To see whether Ntr1 or Ntr2 was required for the release of mature mRNA from the spliceosome, spliceosome formed in mock-depleted or Ntr1-depleted extracts was analyzed by sedimentation on $10 \%-30 \%$ glycerol gradients. As shown in Figure 3B, mature mRNA generated from splicing in either extract sedimented away from the spliceosome (fractions 4-7), in a region of lower glycerol density (fractions 11-13), indicating that Ntr1 was not required for the release of mRNA from the spliceosome. In Ntrl-depleted extracts, lariat-intron accumulated in a large amount and remained associated with the spliceosome (fractions 4-7), suggesting that Ntrl was required for the release of lariat-intron from the spliceosome.

Accumulation of pre-mRNA and lariat-intron in Ntr2-depleted cells

Tetrad analysis had revealed that both NTR1 and NTR2 are essential for cell viability (data not shown). To see 
Tsai et al.

A

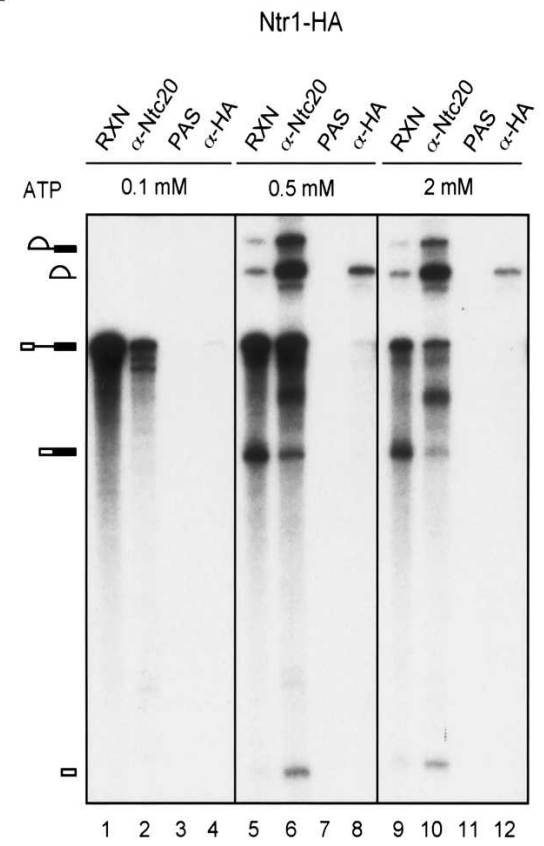

B

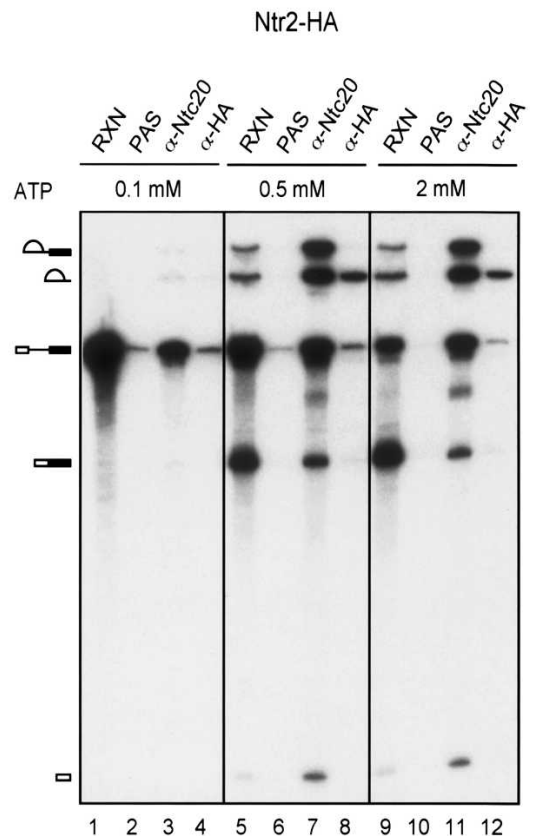

C

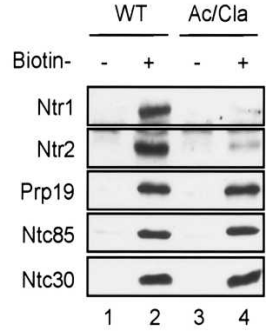

Figure 2. Ntr1 and Ntr2 associate with lariat-intron during the splicing reaction. $(A, B)$ The splicing reaction was performed at $2 \mathrm{mM}$, $0.5 \mathrm{mM}$, and $0.1 \mathrm{mM}$ of ATP in Ntr1-HA $(A)$ and Ntr2-HA $(B)$ extracts, respectively, and reaction mixtures were subjected to immunoprecipitation with anti-HA and anti-Ntc20 antibodies. (C) The splicing reaction was carried out with biotinylated actin or Ac/Cla pre-mRNA and the spliceosome isolated by precipitation with streptavidin Sepharose. Components of the precipitated spliceosome were analyzed by Western blotting using antibodies against Ntr1, Ntr2, Prp19, Ntc85, and Ntc30.

whether this reflected their essentiality in splicing in vivo, yeast strains were constructed such that NTR1 or NTR2 was placed under the control of a GAL-promoter for their metabolic depletion. In glucose-based media, the GAL-NTR1 strain grew normally for unknown reasons (data not shown), but the growth of GAL-NTR2 was suppressed on prolonged incubation, as shown in Figure
4A. RNA was isolated from GAL-NTR2 cells grown in glucose for 0 or $28 \mathrm{~h}$, and subject to primer extension analysis using an $5^{\prime}$ end-labeled primer, R13, complementary to a region in the second exon of the U3 gene. Figure 4B shows that two extension products representing pre-mRNA of U3A and U3B accumulated at $28 \mathrm{~h}$ (lane 5), but not at $0 \mathrm{~h}$ (lane 4) or in the wild-type control
A

Figure 3. Failure of lariat-intron release in Ntr1- or Ntr2-depleted extracts. (A) Splicing was carried out in Prp19-, Ntr1-, or Ntr2-depleted extracts, depleted from Prp19-HA, Ntr1-HA, and Ntr2-HA extracts, respectively, with the anti-HA antibody. (B) Splicing reactions carried out in mock-depleted (top panel) or Ntr1-depleted (bottom panel) extracts were subjected to sedimentation on $10 \%-30 \%$ glycerol gradients. RNA was extracted from fractions collected from each gradient and analyzed on $8 \%$ acrylamide/8 M urea gels.
B
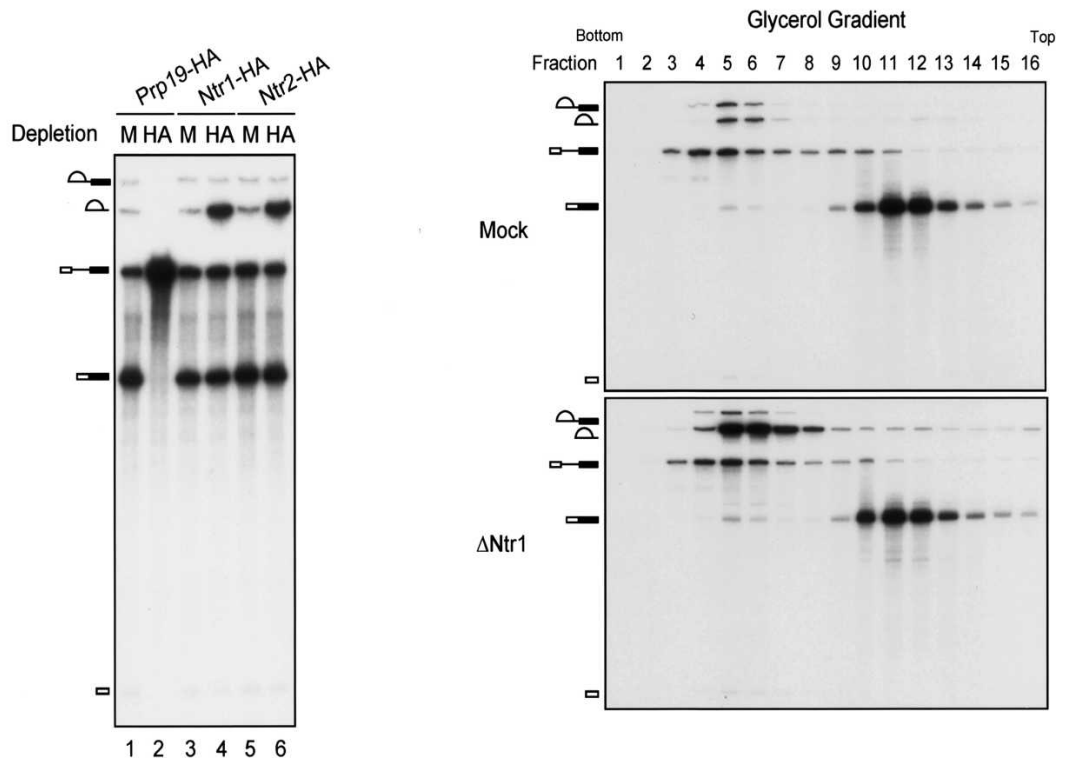
A

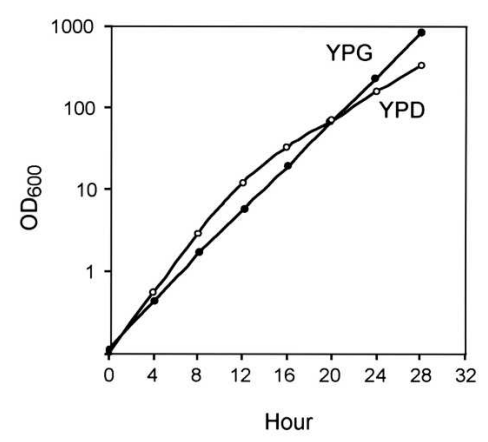

B

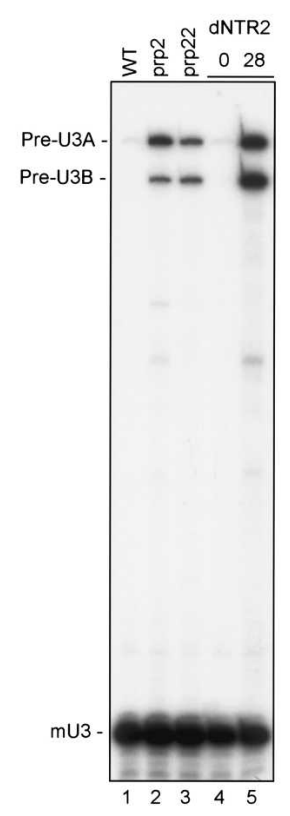

C

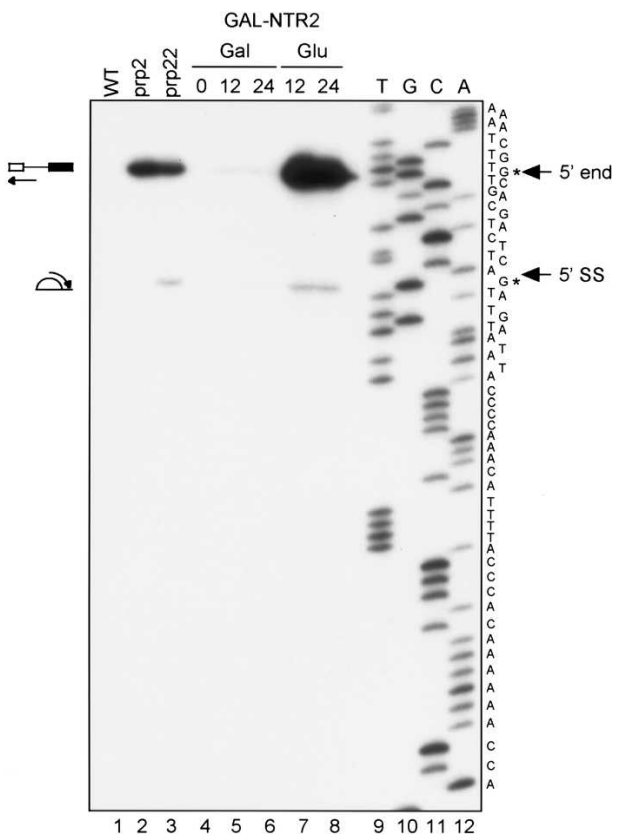

Figure 4. Splicing defect in Ntr2-depleted cells. $(A)$ Growth curves of GAL-NTR2 in YPG and YDP cultures. $(B)$ Primer extension of RNA isolated from wild-type, prp2, prp22, and GAL-NTR2 cells grown in YPD for 0 and $28 \mathrm{~h}$, using primer R13. The prp2 and prp22 mutants were grown at $37^{\circ} \mathrm{C}$ for $2 \mathrm{~h}$ before being harvested. (C) Primer extension using primer R14. GAL-NTR2 cells were grown in YPG (lanes 5,6) or YPD (lanes 7,8) for 12 and 24 h. Asterisks mark the base of the extension stop. (5' SS) 5' splice site.

(lane 1). Similar extension products were also seen in prp2 and prp22 temperature-sensitive mutants after they were grown at restrictive temperatures for $2 \mathrm{~h}$ (Fig. 4B, lanes 2,3). This indicates that in vivo depletion of Ntr2 gave rise to a defect in pre-mRNA splicing. Considering the role of Ntr2 in spliceosome disassembly, depletion of Ntr2 should cause accumulation of lariat-intron, which cannot be detected by extension with R13. A second primer R14, located between the branch point and the 5' splice site of the U3A intron, was used for primer extension to detect the lariat-intron. As shown in Figure 4C, one strong extension stop at the $5^{\prime}$ end of pre-U3A was seen in prp2 (lane 2) and prp22 (lane 3) mutants and in GAL-NTR2 cells grown in glucose medium for 12 and 24 $\mathrm{h}($ lanes 7,8$)$, but was barely detectable in wild type or in GAL-NTR2 grown in galactose medium. This is consistent with the result using primer R13 except that only U3A was detected with primer R14. A minor extension product, representing pre-U3A terminated at the $5^{\prime}$ splice site, was also seen in prp22 (Fig. 4C, lane 3) and GAL-NTR2 grown in glucose medium (Fig. 4C, lanes 7,81 , barely detectable in GAL-NTR2 grown in galactose medium (Fig. 4C, lanes 5,6), and not detectable at all in wild type (Fig. 4C, lane 1) or prp2 (Fig. 4C, lane 2). This indicates that in vivo intron is accumulated when Ntr2 or Prp22 is not functional, corroborating a post-catalytic role for Ntr2 in pre-mRNA splicing.

\section{Association of Ntr1, Ntr2, and Prp43 in a} functional complex

Since in vitro depletion of either Ntr1 or Ntr2 resulted in accumulation of lariat-intron during the splicing reac- tion, these two proteins are either independently required for or coordinately function to promote disassembly of the spliceosome. To determine whether Ntr1 and Ntr2 are associated as a functional unit, Ntr1 was affinity-purified from Ntr1-HA extracts with the anti-HA antibody conjugated to protein A-Sepharose and used for complementation of Ntr1- or Ntr2-depleted extracts. As shown in Figure 5A, affinity-purified Ntr1 did indeed complement the intron-accumulation phenotype of both Ntr1- and Ntr2-depleted extracts (lanes 4,8), suggesting functional association of Ntr1 and Ntr2.

The yeast DExD/H-box family of RNA helicase Prp43 has previously been implicated in spliceosome disassembly (Arenas and Abelson 1997). Prp43 was shown to confer RNA-dependent ATPase activity and to be required for release of the lariat-intron from the spliceosome after completion of the splicing reaction (Martin et al. 2002). Therefore, Prp43 could potentially work cooperatively with Ntr1 and Ntr2 in mediating disassembly of the spliceosome. To test whether Prp43 is functionally associated with Ntr1 and Ntr2, Prp43 was tagged with the V5-epitope and depleted from Prp43-V5 extracts using the anti-V5 antibody. Accumulation of lariat-intron was seen in Prp43-depleted extracts (Fig. 5A, lane 11), but was complemented by affinity-purified Ntr1 (Fig. 5A, lane 12). This suggests that Prp43 is likely associated with Ntr1 and Ntr2 in a functional complex.

Physical association of Ntr1, Ntr2, and Prp43 was confirmed by immunoprecipitation analysis using extracts prepared from double-tagged strains PRP43-V5/NTR1HA and PRP43-V5/NTR2-HA. Splicing extracts from these strains were precipitated with anti-HA or anti-V5 antibodies followed by Western blotting and probed with 
A

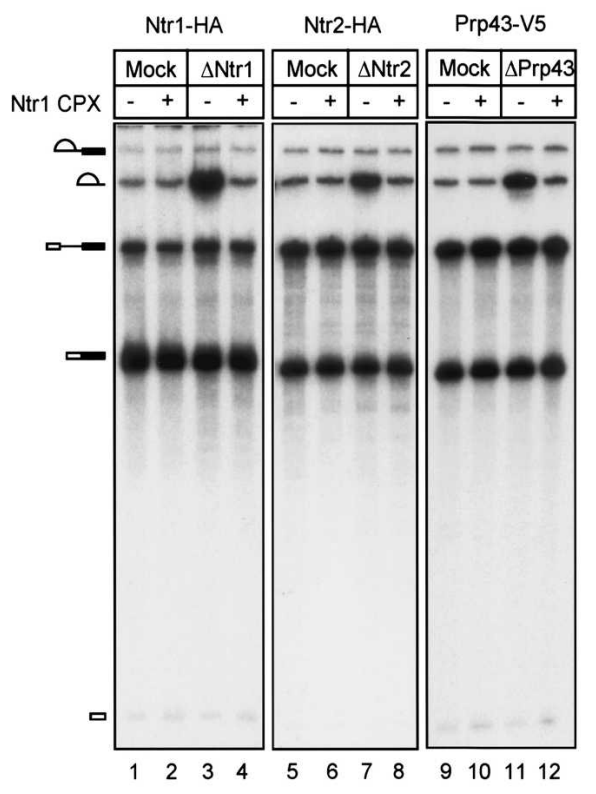

B

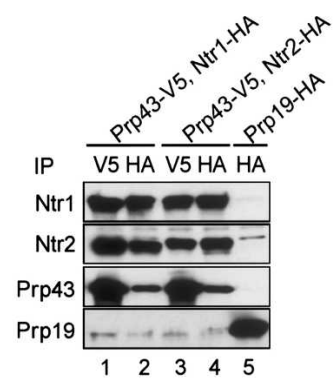

C

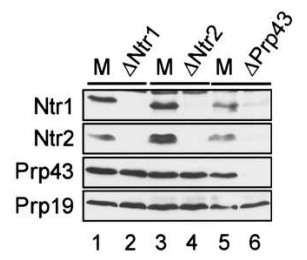

D

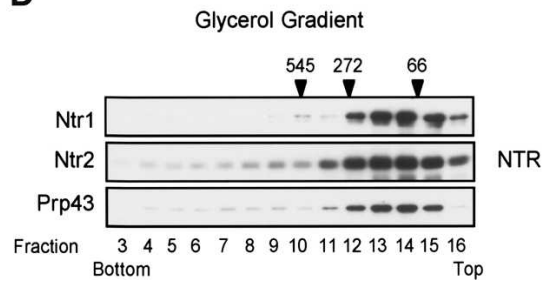

Figure 5. Association of Ntr1, Ntr2, and Prp43 in a functional complex. (A) Ntr1-HA, Ntr2-HA, and Prp43-V5 extracts were depleted of Ntr1, or Ntr2, or Prp43 with anti-HA or anti-V5 antibody, respectively, and used for splicing and complementation assays with purified Ntr1 complex. (B) Prp43-V5/Ntr1-HA (lanes 1,2) and Prp43-V5/Ntr2-HA (lanes 3,4) extracts were immunoprecipitated with anti-V5 (lanes 1,3) or anti-HA (lanes 2,4) antibody followed by Western blotting probed with anti-Ntr1, anti-Ntr2, anti-V5, and anti-Prp19 antibodies. (Lane 5) Prp19-HA extracts were also precipitated with the anti-HA antibody as a control. (C) Western blotting of Ntr1-, Ntr2-, and Prp43-depleted extracts was probed with anti-Ntr1, anti-Ntr2, anti-Prp19 polyclonal, and anti-V5 monoclonal antibodies. Ntr1 was depleted from Prp43-V5/Ntr1-HA extracts with the anti-HA antibody (lanes 1,2), Ntr2 depleted from Prp43-V5/ Ntr2-HA extracts with the anti-HA antibody (lanes 3,4), and Prp43 depleted from Prp43-V5/Ntr1-HA extracts with the anti-V5 antibody (lanes 5,6), respectively. (D) The affinity-purified NTR complex was subjected to sedimentation on $10 \%-30 \%$ glycerol gradients, and proteins from each fraction were analyzed by Western blotting probed for Ntr1, Ntr2, and Prp43. The molecular weight markers are indicated on the top.

polyclonal anti-Ntr1 and anti-Ntr2 antibodies and antiV5 antibody for Prp43-V5. As shown in Figure 5B, precipitation with the anti-V5 antibody for Prp43 coprecipitated Ntr1 and Ntr2 (lanes 1,3), but only minute amounts of Prp19. Precipitation with the anti-HA antibody for Ntr1 coprecipitated Ntr2 and Prp43 (Fig. 5B, lane 2), and that for Ntr2 coprecipitated Ntr1 and Prp43 as well (Fig. 5B, lane 4). Together, these results indicate that Ntr1, Ntr2, and Prp43 are associated in a functional complex that acts to release lariat-intron in disassembly of the spliceosome. The complex is named NTR complex, which could be isolated by affinity purification with the anti-HA antibody from Ntrl-HA extracts for the following studies.

Further examination of proteins in depleted extracts by Western blotting revealed that depletion of Ntr1 resulted in codepletion of Ntr2, and vice versa, but did not significantly affect the amount of Prp43 as shown in Figure 5C (lanes 1-4), whereas depletion of Prp43 code- pleted $\sim 70 \%$ of Ntr1 and Ntr2 (lanes 5,6). The level of Prp19 was not significantly affected in any of these depleted extracts. These results indicate that although Ntr1, Ntr2, and Prp43 were associated as a functional complex in mediating spliceosome disassembly, they were not present in stoichiometry. While Ntr1 and Ntr2 appeared to always associate with each other, the majority of Prp43 was not in complex with Ntr1 and Ntr2, and $\sim 30 \%$ of Ntr1 and Ntr2 were in a complex free of Prp43. This further indicates that neither Prp43 nor Ntr1-Ntr2 complex functioned in releasing lariat-intron in the absence of each other.

The existence of Ntr1-Ntr2-Prp43 trimeric complex was confirmed by sedimentation analysis of the Ntr1 complex purified with the anti-HA antibody from Ntr1HA extracts. The affinity-purified complex was fractionated on a $10 \%-30 \%$ glycerol gradient, and each fraction was analyzed for Ntr1, Ntr2, and Prp43 by Western blotting. As shown in Figure 5D, Ntr1, Ntr2, and Prp43 
cosedimented primarily in fractions $12-15$, corresponding to a size of $150-200 \mathrm{kDa}$, consistent with the calculated size of the trimeric complex. The minor form of Ntr1-Ntr2 dimer is presumed to copurify with the trimer, but was not clearly distinguished.

\section{Interactions between Ntr1, Ntr2, and Prp43}

Large-scale genomic studies have revealed physical interactions between Ntr1 and Ntr2 and between Ntr1 and Prp43 (Gavin et al. 2002; Hazbun et al. 2003). Genomewide two-hybrid analyses have also identified interactions between Ntr1 and Ntr2 (Ito et al. 2001; Hazbun et al. 2003). To confirm and further characterize interactions between these three proteins in the complex, interactions between each pair of proteins were analyzed by two-hybrid assays. Ntr1, Ntr2, and Prp43 were individually fused to the LexA-DNA-binding domain and GAL4-activation domains, and interactions were assayed by measuring $\beta$-galactosidase activity. Figure 6A shows that Ntr1 interacted with Ntr2, Prp43, and itself, whereas Ntr2 and Prp43 interacted only with Ntr1. Thus, formation of the NTR complex might be mediated through interactions of Ntr1 with Ntr2 and Prp43.

A recent study has found that the DExD/H-box RNA helicase $\operatorname{Prp} 2$, which is required for the first catalytic reaction, binds to the spliceosome through an interac- tion between the G-patch domain containing protein Spp2 (Roy et al. 1995; Silverman et al. 2004). Such interaction requires the G-patch domain of Spp2 and a region at the C-terminal end of the Prp2 sequence (Silverman et al. 2004). It has been proposed that Spp2 serves as a Prp2 accessory factor for targeting Prp2 to the spliceosome (Silverman et al. 2004). Interestingly, Ntr1 also contains a G-patch domain near its $\mathrm{N}$ terminus (Fig. 1). We therefore examined whether the G-patch domain or other regions of $\mathrm{Ntrl}$ was responsible for the interaction between Ntr1 and Prp43 by two-hybrid assays. A series of deletion mutants spanning over the entire Ntrl sequence were generated, and the position of the deleted region in each deletion mutant is shown in Figure 6B. Interactions of these deletion mutants fused to the LexADNA-binding domain, with Prp43, Ntr2, and Ntr1 fused to the GAL4-activation domain, were assayed by measuring $\beta$-galactosidase activity. As shown in Figure 6C, deletion of the G-patch domain alone, or in combination with the upstream $(\Delta \mathrm{NG})$ or downstream region $(\Delta \mathrm{A})$ from Ntrl abolished the interaction between Ntrl and Prp43, suggesting the requirement of the G-patch domain for Ntr1's interaction with Prp43. Moreover, a Gpatch domain containing an $\mathrm{N}$-terminal fragment with amino acid residues 1-122 (NG) was sufficient for interactions between Ntr1 and Prp43. The G-patch domain was not required for the interaction between Ntrl and Ntr2 or for Ntr1 self-interaction, since neither $\Delta \mathrm{G}$ nor

A

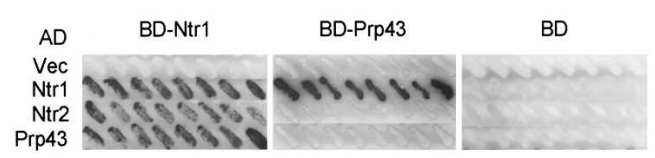

B

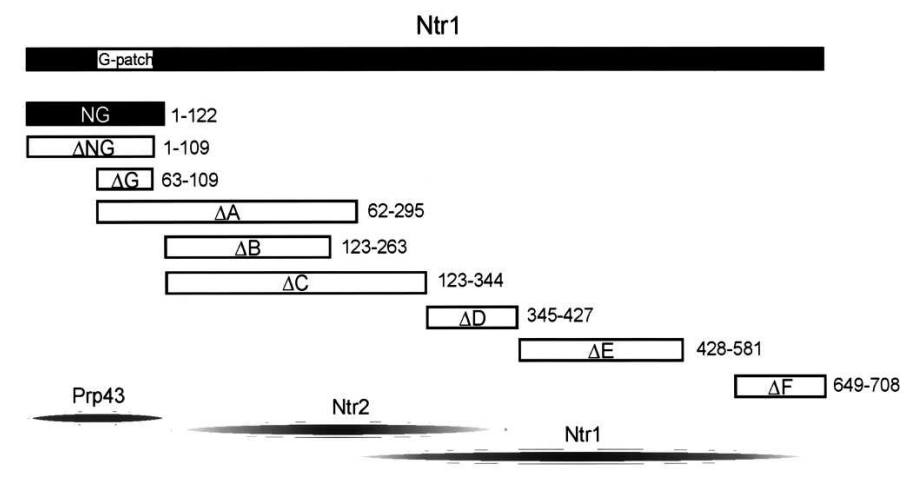

Figure 6. Two-hybrid analysis of interactions between Ntr1, Ntr2, and Prp43. (A) Ntr1, Ntr2, and Prp43 were fused to the LexA-DNA-binding domain and Ntr1 and Prp43 fused to the GAL4-activation domain, and interactions were assayed by measuring $\beta$-galactosidase activity. (B) The map of Ntrl and the positions of deletion mutants constructed for two-hybrid assays. Fragment NG, shown in the solid box, contains amino acid residues 1-122. Regions of deletion, shown in the open boxes, are $\Delta \mathrm{NG}, 1-109 ; \Delta \mathrm{G}, 63-109 ; \Delta \mathrm{A}, 62-295 ; \Delta \mathrm{B}$, $122-263 ; \Delta \mathrm{C}, 123-344 ; \Delta \mathrm{D}, 345-427 ; \Delta \mathrm{E}, 428-581 ; \Delta \mathrm{F}$, 649-708. Regions of Ntr1 interact with Prp43; Ntr2 and Ntrl self-interaction are indicated on the bottom. $(C)$ Deletion mutants of Ntr1 were fused to the LexA-DNAbinding domain and their interactions with Prp43, Ntr1, and Ntr2, fused to the GAL4-activation domain, were assayed by measuring $\beta$-galactosidase activity. Far left panel $(\mathrm{AD})$ shows the background generated from each deletion mutant when fused to the DNA-binding domain. 
$\Delta$ NG had any effect on their interactions. Further analysis of deletion mutants revealed that while $\Delta \mathrm{C}$ completely abolished interactions between Ntr1 and Ntr2, $\Delta \mathrm{D}$ moderately and $\Delta \mathrm{B}$ greatly weakened the interaction. The interaction in the $\Delta \mathrm{A}$ mutant appeared to be at a level similar to the control of the activation domain (Fig. 6C, far left panel). These results suggest that the maximal region required for interactions between Ntr1 and Ntr2 was between amino acid residues 123 and 427. In contrast, self-interaction of Ntrl involved the carboxyl half of the protein since $\Delta \mathrm{C}, \Delta \mathrm{D}$, and $\Delta \mathrm{E}$ completely abolished the interaction, but $\Delta \mathrm{B}$ had no effect. The interaction in $\Delta \mathrm{F}$ was also weakened in view of the high basal level in this mutant.

NTC is associated with the Ntr1-and Ntr2-containing spliceosome

Although the lariat-intron coprecipitated with Ntr1 and Ntr2 during the splicing reaction, the amount precipitated was much lower than that coprecipitated with Ntc20 (Fig. 2). This could reflect a differential efficiency of precipitation by different antibodies or that Ntr1 and Ntr2 might be only transiently associated with the intron-containing spliceosome either while NTC was still on the spliceosome or after NTC was dissociated. To test whether Ntr1 and Ntr2 coexist with NTC on the spliceosome, we performed a double immunoprecipitation experiment. The spliceosome formed in Ntr1-HA extracts was immunoprecipitated with anti-HA antibody and eluted with the HA-peptide. The eluted spliceosome was then immunoprecipitated with an anti-Ntc20 antibody to examine the presence of NTC. As shown in Figure 7, the spliceosome coprecipitated with Ntr1 predominantly contained lariat-introns (lane 3 ) that, upon

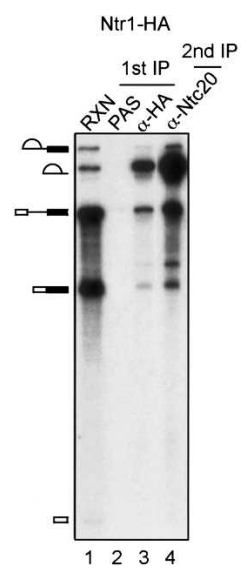

Figure 7. Association of NTC with the Ntr1-containing spliceosome. (Lane 3) Spliceosome formed in Ntr1-HA extracts was immunoprecipitated with anti-HA antibody. (Lane 4) The precipitate was eluted with the HA-peptide, and the eluted materials were precipitated again with anti-Ntc20 antibody. (RXN) Reaction; (PAS) protein A-Sepharose. The reaction mixture loaded in lane 1 was one-twentieth of that precipitated by the anti-HA antibody. The material loaded in lane 3 was one-tenth of that precipitated by the anti-Ntc20 antibody. elution from beads with the HA-peptide, could be precipitated by the anti-Ntc20 antibody (lane 4), indicating that NTC was still present on the spliceosome when Ntr1 joined. This also suggested the possibility of isolating NTC-containing spliceosome formed in Ntr1-depleted extracts for functional assay of NTR complex.

\section{Disassembly of the spliceosome mediated by NTR complex}

To assay the function of NTR complex, the splicing reaction was carried out in Ntr1-depleted extracts and the intron-accumulated spliceosome isolated by precipitation with the anti-Ntc20 antibody as shown in Figure 8A (lane 2). When the affinity-purified NTR complex and ATP were added to the precipitated spliceosome, $70 \%$ of the lariat-intron was released from beads following incubation (Fig. 8A, lanes 9,10). Incubation with NTR complex or ATP alone failed to release lariat-intron (Fig. 8A, lanes 5-8). Hydrolysis of ATP was required for lariatintron release as revealed by the low efficiency of intron release with $\gamma \mathrm{S}$-ATP (Fig. 8A, lanes 11,12). This suggests that NTR complex promotes dissociation of NTC from spliced lariat-intron RNA in an ATP-dependent manner. To see whether NTR complex also promoted dissociation of snRNPs from lariat-intron, a similar experiment was performed except that the intron-containing spliceosome was precipitated with the anti-Smdl antibody. As shown in Figure $8 \mathrm{~B}, \sim 50 \%$ of the lariat-intron precipitated by the anti-Smd 1 antibody was released from beads upon incubation with ATP and NTR complex (lanes 5,6), indicating dissociation of the intron from snRNPs. Together, these results show that NTR complex catalyzed the dissociation of lariat-intron from NTC as well as from snRNPs, possibly as free RNA. To confirm that lariat-intron was released as free RNA, the dissociated fraction was treated with proteinase $\mathrm{K}$ and subjected to gradient sedimentation, as shown in Figure 8C. Gradient I shows the total splicing reaction performed in Ntr1depleted extracts; the spliceosome sedimented primarily in fractions 5-7 and mature mRNA in fractions 11 and 12 (see also Fig. 3B). Gradient II shows that the dissociated lariat-intron sedimented near the top of the gradient in a position (fractions 13 and 14) lighter than mature mRNA. Nearly an identical profile was seen when this fraction was deproteinized prior to sedimentation, as shown in gradient III, indicating that the lariat-intron had been released from the beads as naked RNA.

To see whether snRNPs were separated from each other accompanying intron dissociation, fractions released from anti-Ntc20 antibody precipitated spliceosome were subject to sedimentation on glycerol gradient, and RNA was extracted from each fraction for Northern blotting probed with five snRNAs. As shown in Figure 9, released U2, U5, and U6 sedimented at different positions (top panel), indicating separation of these three snRNPs. For comparison, total splicing extracts (Fig. 9, bottom panel) and deproteinized extracts (Fig. 9, middle panel) were also subject to sedimentation to reveal the positions of individual snRNPs and naked snRNAs. In- 
A

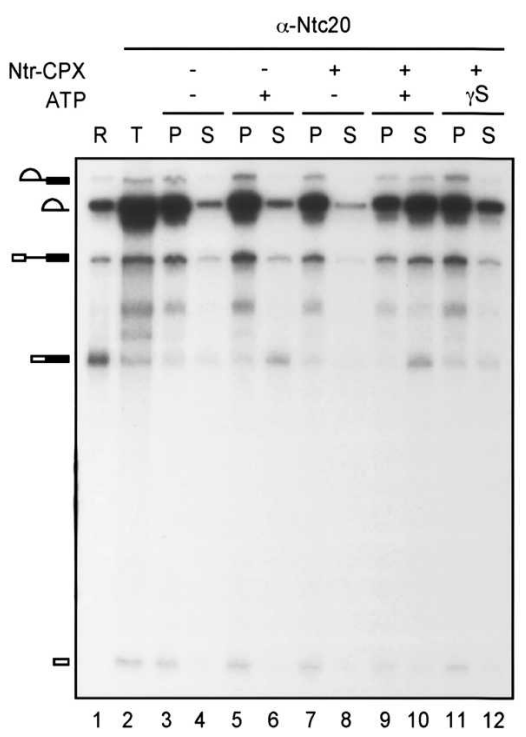

B

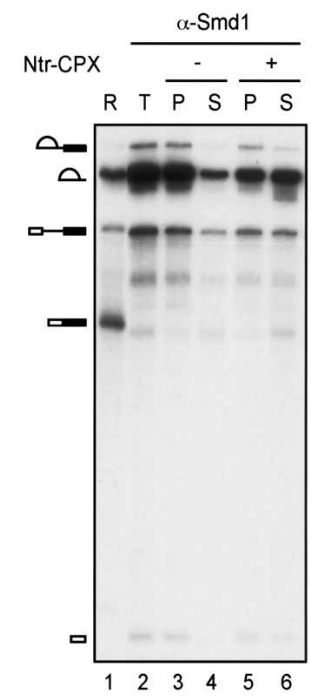

C

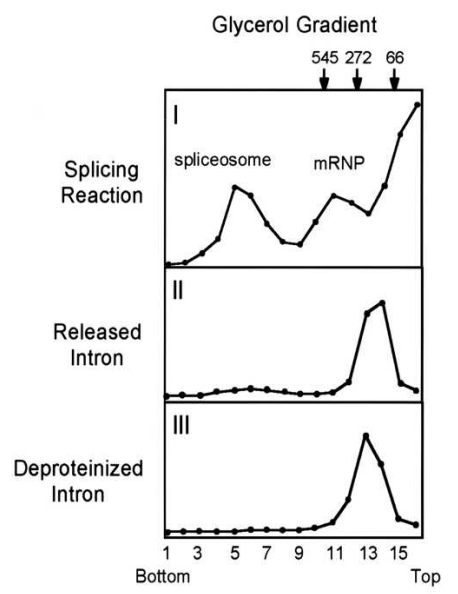

Figure 8. Dissociation of lariat-intron as naked RNA catalyzed by NTR complex. (A) Splicing was carried out in Ntr1-depleted extracts and the reaction mixture (lane 1) was precipitated with the anti-Ntc20 antibody (lane 2). (Lanes 3-12) The affinity-purified NTR complex and/or ATP/ $\gamma$ S-ATP was added to the precipitate. After incubation, released materials were separated from pellets as supernatant fractions for RNA analysis. $(B)$ As in $A$, except that the splicing reaction mixture (lane 1) was precipitated with the anti-Smd1 antibody (lane 2), and the precipitates were incubated without (lanes 3,4) or with (lanes 5,6) NTR complex in the presence of ATP. $(C)$ Gradient sedimentation of total splicing reaction in Ntr1-depleted extracts (I), released intron fraction (as in $A$, lane 10) prior to (II) and after (III) deproteinization. (R) Reaction; (T) total precipitate; (P) pellet; (S) supernatant; (NTR-CPX) affinity-purified NTR complex.

terestingly, while the released U5 sedimented like that in the extract, U2 was dissociated as a lighter particle than that in the extract, but not as naked RNA. This suggests that some components of U2 snRNP might have been dissociated during spliceosome assembly or disassembly or U2 might be dissociated in an altered conformation. Furthermore, U6 was released as naked RNA, consistent with our previous observation that Lsm proteins were dissociated from U6 during spliceosome activation (Chan et al. 2003). Altogether, these results demonstrate that NTR complex was functional in catalyzing disassembly of the spliceosome, resulting in total separation of U2, U5, U6, NTC, and lariat-intron.

\section{Discussion}

In this study, we have identified two novel splicing factors involved in disassembly of the spliceosome. Ntr1 and Ntr2 were identified through their association with NTC components. Nevertheless, only a small fraction of Ntr1 and Ntr2 was associated with NTC since depletion of NTC from the splicing extract did not affect the amount of Ntr1 or Ntr2 to a large extent (data not shown), and vice versa, only a small fraction of NTC components was associated with Ntr1 and Ntr2, as depletion of Ntr1 or Ntr2 did not affect the function of NTC in spliceosome activation. It is not clear why small amounts of Ntr1, Ntr2, and NTC are associated with each other. Since nuclease treatment of splicing extracts did not abolish such association (data not shown), the interaction was unlikely to be mediated through binding of RNA, excluding the possibility of their being the endogenous spliceosome. The functional significance of such association remains unknown.

Both NTR1 and NTR2 are essential for cellular growth. Metabolic depletion of Ntr2 resulted in accumulation of pre-mRNA and lariat-intron, indicating requirement of Ntr2 for pre-mRNA splicing in vivo. Although the in vivo role of Ntr1 in splicing was not demonstrated, it is likely that Ntr1 is also essential for pre-mRNA splicing in vivo, considering that Ntr1 was tightly associated with Ntr2 and the two proteins functioned in a coordinative manner. Primer extension analysis revealed that despite the NTR complex not being required for splicing catalysis or prior steps of spliceosome assembly, premRNA accumulated at much higher levels than lariatintron upon depletion of Ntr2. It is conceivable that block of spliceosome disassembly due to a faulty NTR complex will result in accumulation of the spliceosome and failure in recycling spliceosomal components. As a consequence, a large part of pre-mRNA cannot be spliced and accumulates in the cell. This can be demonstrated in vitro using a splicing recycling assay described previously (Supplementary Fig. S1; Raghunathan and Guthrie 1998). Consistently, cells carrying mutations in the PRP22 gene, defective in release of mature mRNA, also accumulated much more pre-mRNA than lariat-intron.

We have demonstrated that Ntr1 and Ntr2 were associated with Prp43 to form a trimeric complex. While Ntr1 and Ntr2 were always associated with each other, 


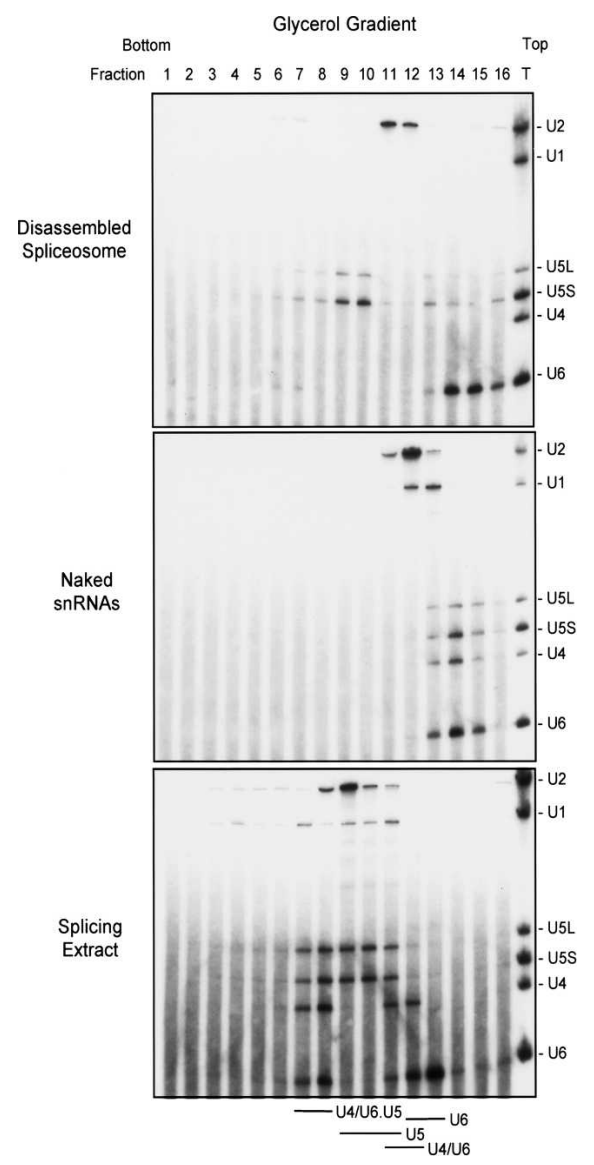

Figure 9. Dissociation of snRNPs catalyzed by the NTR complex. The released fraction as in Figure 8A (top), total extracts (bottom), and deproteinized extracts (middle), were subjected to sedimentation on $10 \%-30 \%$ glycerol gradient, and RNA was extracted from each fraction for Northern blotting, probed with U1, U2, U4, U5, and U6. The positions of U5, U6, U4/U6 disnRNP, and U4/U6.U5 tri-snRNPs are marked.

Prp43 appeared to exist in great excess, and a large fraction of Prp43 was not associated with either Ntr1 or Ntr2. Furthermore, $\sim 30 \%$ of Ntr1 and Ntr2 were not associated with Prp43. Thus, these three proteins existed in at least three different forms, uncomplexed Prp43, Ntr1-Ntr2 heterodimer, and Ntr1-Ntr2-Prp43 heterotrimer. The Ntr1-Ntr2-Prp43 trimeric complex was the functional form that mediated spliceosome disassembly. Uncomplexed Prp43 did not function by itself since depletion of Ntr1 or Ntr2 without changing the level of Prp43 to any great extent resulted in the accumulation of lariat-intron in the splicing reaction. Depletion of Prp43 from splicing extracts also led to intron accumulation despite a fraction of Ntr1 and Ntr2 being still present, suggesting that the Ntr1-Ntr2 dimeric complex was not functional without Prp43.

Prp43 belongs to the family of DExD/H-box RNA helicases, which play important roles in pre-mRNA splicing throughout the whole splicing process. Eight DExD/ H-box RNA helicases are involved in different steps of the splicing reaction (Staley and Guthrie 1998). All
DExD/H-box family proteins confer RNA-dependent ATPase activity, and some have also demonstrated RNA unwinding activity (Laggerbauer et al. 1998). These proteins use the energy gained from ATP hydrolysis to unwind RNA duplexes or to drive conformational changes in RNA molecules or ribonucleoprotein complexes. Nevertheless, DExD/H-box RNA helicases show very little substrate specificity for unwinding of RNA duplexes in vitro. It is speculated that these helicases might require extrinsic factors for targeting to specific substrates to execute their normal functions. Factors that interact with RNA helicases and possibly play roles in regulating their functions have been documented (Silverman et al. 2003). The pre-mRNA splicing factor Spp2, initially identified as a high-copy suppressor of the prp2-1 temperature-sensitive mutant (Last et al. 1987), has been shown to be required for the activity of Prp2 in promoting step one reaction (Silverman et al. 2004). Interactions of Prp2 and Spp2 can be demonstrated by twohybrid and GST pull-down assays (Roy et al. 1995; Silverman et al. 2004). Spp2 also contains a G-patch motif important for its interaction with Prp2 (Silverman et al. 2004). It has been proposed that the interaction of Prp2 with Spp2 is essential for the function of Prp2, and that Spp2 might act as a cofactor of Prp2 in determining its spliceosome specificity (Silverman et al. 2004). Similarly, Prp43 interacts with Ntr1 through the G-patch domain, and the association of Prp43 with Ntr1 and Ntr2 is required for spliceosome disassembly. Ntr1 and Ntr2 together might function as coordinators to target Prp43 to the spliceosome to mediate spliceosome disassembly. Whether the G-patch motif represents a general DExD/H RNA helicase-interacting motif for directing the helicase to specific substrate remains to be seen.

Both NTR1 and NTR2 are essential for vegetative yeast growth and at least Ntr2 is essential for efficient splicing in vivo. Nevertheless, proteins homologous to either Ntr1 or Ntr2 have not been identified in other organisms despite the fact that Prp43 is evolutionarily conserved (Fouraux et al. 2002). It is possible that the metazoan Prp43 is evolved to carry extra domains for targeting to its substrate, substituting the function of trans-acting regulators. Indeed, the metazoan Prp43 has a highly charged $\mathrm{N}$-terminal domain not present in yeast or Caenorhabditis elegans. Determining whether this N-terminal region is functional for interaction with other spliceosomal components awaits further study.

Although Prp43 required Ntr1 and Ntr2 for its targeting to the spliceosome, only a small fraction of Prp43 was associated with Ntr1 and Ntr2. It is not clear whether the remaining protein exists in a free form or is associated with other macromolecules. The human ortholog of Prp43, DDX15 or hPrp43, has been demonstrated to associate with human La autoantigen and accumulate in the nucleoli of Hep-2 cells (Fouraux et al. 2002), suggesting a possible function of hPrp43 other than splicing. Association of hPrp43 with U1 and U2 snRNAs was also shown by immunoprecipitation with antibodies against hPrp43 (Fouraux et al. 2002). Furthermore, hPrp43 was found associated with the affinity-pu- 
rified 17S U2 snRNP (Will et al. 2002). These results suggest that hPrp43 might also function at the early stage of spliceosome assembly or even in facilitating the assembly of U1 or U2 snRNP. Nevertheless, association of yeast Prp43 with U1 or U2 was not detected by immunoprecipitation analysis (data not shown). Neither were early steps of the splicing reaction affected in the absence of Prp43. This suggests that the yeast Prp43 could be deficient in these extra functions that hPrp43 might have.

The fact that Ntr1 and Ntr2 coprecipitated a small amount of lariat-intron from the splicing reaction suggests that these two proteins might be only transiently associated with the spliceosome after completion of the splicing reaction. It is conceivable that the spliceosome rapidly undergoes disassembly upon binding of NTR complex and, consequently, this results in the detection of only a low level of Ntr1-Ntr2-associated spliceosome. In contrast, in normal splicing reactions, Prp43 was not detected to stably associate with the spliceosome in any amount by immunoprecipitation analysis using either anti-V5 antibody for Prp43-V5 or a polyclonal antibody against Prp43 (data not shown), suggesting that Prp43 did not act concordantly with Ntr1 and Ntr2 in binding to the spliceosome. It is possible that Prp43, while binding to the spliceosome as a component of NTR complex, might be immediately dissociated from the spliceosome upon hydrolysis of ATP, triggering disintegration of the spliceosome that still contains Ntr1 and Ntr2. The detected Ntr1- and Ntr2-containing splicing complex might represent a disassembly intermediate, which is either on its way to disassembly or defective for further disassembly. In this case, following disassembly of the spliceosome, Ntr1 and Ntr2 would need to reassociate with Prp43 to form the functional complex for subsequent rounds of the reaction. Alternatively, Prp43 might be associated with Ntr1 and Ntr2 in a dynamic manner. Ntr1-Ntr2 dimeric complex could be recruited to the spliceosome and form a relatively more stable complex, as detected by immunoprecipitation of Ntr1 or Ntr2. The Ntr1-Ntr2-bound spliceosome may further recruit Prp43 to drive disassembly of the spliceosome, with either Prp43 dissociating first or dissociating together with Ntr1 and Ntr2.

\section{Materials and methods}

\section{Yeast strains}

The following yeast strains were used: BJ2168, Mata prc1 prb1 pep4 leu2 trp1 ura3; YSCC1, Mata prc1 prb1 pep4 leu2 trp1 ura3 PRP19HA; YSCC131, Mata prc1 prb1 pep4 leu2 trp1 ura3 NTR1HA; YSCC132, Mata prc1 prb1 pep4 leu2 trp1 ura3 NTR2HA; YSCC133, Mata prc1 prb1 pep4 leu2 trp1 ura3 PRP43V5; YSCC141, Mata prc1 prb1 pep4 leu2 trp1 ura3 NTR1HA PRP43V5; YSCC142, Mata prc1 prb1 pep4 leu2 trp1 ura3 NTR2HA PRP43V5; YSCC152, Mata prc1 prb1 pep4 leu2 trp1 URA3::GAL-NTR2; J401, Mata his3 his7 ade3 ura3 prp2-1; prp22, Mata ade2 his3 ura3 tyr1 prp22-1.

\section{Oligonucleotides}

The following oligonucleotides were used: R1, GGCCGAC GTCCCAGACTACGCTTAGAAAGTACCTATAAAAGAGG; R2, GGCCGACGTCGTATGGGTAGAGGTCAAGGGCCCA TAAAT; R3, GGCCGGATCCTAGAACTATCGGAGATCAG; R4, CCGGTCGAGATTGAAGGTCAATGATAGA; R5, GGC CGACGTCCCAGACTACGCTTGAACGTTAATCATGTTA TTT; R6, GGCCGACGTCGTATGGGTAGTTACCAATGAG CTTATTTATTAGG; R7, GGCCGGATCCATTGTTGGACA GTGAGG; R8, CCGGCTCGAGGTAGTGACGAAGATGCC; R9, GGCCGGATCCGGTATCCATAAGTGGTG; R10, CCG GAAGCTTTTTCTTGGAGTGCTTAC; R11, CCGGACTAG TTAGACATTTTGTGTGA; R12, CCGGCTCGAGCTCTCC GACAACGGTGA; R13, GAGTGACGATTCCTATAG; R14, AAGCCTGCTCCGAAATG.

\section{Antibodies and reagents}

The anti-V5 antibody was purchased from Invitrogen Inc. The anti-HA monoclonal antibody $8 \mathrm{G} 5 \mathrm{~F}$ was produced by immunizing mice with a KLH-conjugated HA-peptide (R.-T. Tsai and S.-C. Cheng, unpubl.), and anti-Ntr2 polyclonal antibody was produced by immunizing rabbits with the Escherichia coli expressed full-length protein. Anti-Ntr1 and anti-Prp43 antibodies were produced by immunizing rabbits with the $E$. coli expressed Ntr1 C-terminal fragment of amino acid residues 563-709 and Prp43 N-terminal fragment of amino acid residues 1-101, respectively. Protein A-Sepharose was from Amersham Inc., Streptavidin Sepharose from Sigma Inc., and SuperScript II from Life Technology.

\section{Construction of NTR1-HA-tagged, NTR2-HA-tagged,} and PRP43-V5-tagged strains

For construction of the NTR1-HA-tagged strain, two DNA fragments, A and B, were generated by polymerase chain reaction (PCR) using primers $\mathrm{R} 1$ and $\mathrm{R} 4$, and $\mathrm{R} 2$ and $\mathrm{R} 3$, respectively. Following digestion of fragment A, which contains 436 base pairs (bp) of the $3^{\prime}$ end of the NTR1 ORF and the $5^{\prime}$ half of the HA-epitope, with BamHI and AatII, and digestion of fragment B, which contains 609 bp of the $3^{\prime}$ untranslated region (UTR) and the $3^{\prime}$ half of the HA-epitope, with AatII and XhoI, fragments A and B were ligated into plasmid vector pRS406 digested with BamHI and XhoI. The resulting plasmid was linearized with BclI for transformation into yeast strain BJ2168 to displace the wildtype allele with the HA-tagged allele by the pop-in and pop-out gene displacement method (Winston et al. 1983). For construction of the NTR2-HA-tagged strain, DNA fragments C and D were generated by PCR using primers R5 and R8 and R6 and R7, respectively. Following digestion of fragment $\mathrm{C}$, which contains 471 bp of the $3^{\prime}$ end of the NTR2 ORF and the $5^{\prime}$ half of the HA-epitope, with BamHI and AatII, and digestion of fragment D, which contains 502 bp of the 3' UTR and the 3' half of the HA-epitope, with AatII and XhoI, fragments C and D were ligated with pRS406 digested with BamHI and Xhol. The resulting plasmid was linearized with BglII for transformation into yeast strain BJ2168 to displace the wild-type allele with the HA-tagged allele. For construction of the PRP43-V5-tagged strain, DNA fragments $\mathrm{E}$ and $\mathrm{F}$ were generated by PCR using primers R9 and R10 and R11 and R12, respectively. Fragment E, which contains $510 \mathrm{bp}$ of the $3^{\prime}$ end of the PRP43 ORF, was digested with BamHI and HindIII and ligated with plasmid vector pDK85 digested with BamHI and HindIII. The resulting plasmid was digested with SpeI and XhoI, and ligated with fragment F, which contains 599 bp of the 3' UTR, and had previously been digested with SpeI and XhoI. The resulting plasmid was linear- 
ized with MscI for transformation into yeast strain BJ2168 to displace the wild-type allele with the V5-tagged allele.

\section{Primer extension}

Primer extension was performed with SuperScript II reverse transcriptase based on the method of Chan et al. (2003) using primer R13 or R14. Extension products were analyzed by electrophoresis on $8 \%$ polyacrylamide/8 M urea gels.

\section{Preparation of splicing extracts and substrates}

Yeast whole-cell extracts were prepared according to Cheng et al. (1990). Actin precursors were synthesized in vitro, using SP6 RNA polymerase according to Cheng and Abelson (1987), and biotinylated pre-mRNA was synthesized following the procedure described by Chan et al. (2003).

Splicing assays, immunoprecipitation, immunodepletion, and precipitation of the spliceosome by streptavidin agarose

Splicing assays were carried out according to Cheng and Abelson (1987). Immunoprecipitation was performed as described by Tarn et al. (1993a) with the anti-HA or anti-Ntc20 antibody. Immunodepletion of Ntr1, Ntr2, and Prp43 was performed by incubation of $0.1 \mathrm{~mL}$ each of NTR1-HA, NTR2-HA, and PRP43V5 splicing extract with $150 \mathrm{ng}$ of anti-HA antibody or $15 \mu \mathrm{L}$ of anti-V5 antibody, respectively, conjugated to $50 \mu \mathrm{L}$ of protein A-Sepharose. Precipitation of the spliceosome with streptavidin agarose was carried out according to Chan et al. (2003).

\section{Purification of NTR complex}

NTR1-HA strain was grown in $10 \mathrm{~L}$ of YPD for preparation of splicing extracts and the $40 \%$ saturated ammonium sulfate pellet fraction (40P) of the extract according to Cheng et al. (1990). The anti-HA antibody was conjugated to protein A-Sepharose at a final concentration of $2 \mathrm{mg} / \mathrm{mL}$ and cross-linked with dimethylpimelimidate. Approximately $150-200 \mathrm{mg}$ of $40 \mathrm{P}$ were added to $\mathrm{KPO}_{4}$ (pH 7.0) to a final concentration $60 \mathrm{mM}$, and applied to $0.1 \mathrm{~mL}$ of the anti-HA antibody-conjugated protein A-Sepharose column pre-equilibrated with Buffer DK $(20 \mathrm{mM}$ HEPES at $\mathrm{pH}$ 7.9, $60 \mathrm{mM} \mathrm{KPO}_{4}$ at $\mathrm{pH} 7.0,0.2 \mathrm{mM}$ EDTA, $50 \mathrm{mM} \mathrm{NaCl}, 20 \%$ glycerol). After recycling three times, the column was washed with $2 \mathrm{~mL}$ of Buffer DK containing 0.05\% Nonidet P-40 (NP-40) and then $1 \mathrm{~mL}$ of Buffer DK without NP-40. These procedures were performed at $4^{\circ} \mathrm{C}$. The resin was resuspended in $1 \mathrm{~mL}$ of Buffer DK, transferred to an Eppendorf tube, and brought to room temperature. The bound materials were then eluted by incubation at room temperature for $5 \mathrm{~min}$ with $0.2 \mathrm{~mL}$ of 0.2 mM HA peptide diluted in Buffer DK. The elution step was repeated six times, and individual fractions were collected.

\section{Spliceosome disassembly assays}

Splicing reactions were carried out in Ntr1-depleted extracts under normal conditions. Twenty-microliter aliquots of the reaction mixture were precipitated with $1 \mu \mathrm{L}$ of anti-Ntc20 antibody conjugated to $10 \mu \mathrm{L}$ of protein A-Sepharose. After washing, the precipitate was incubated with $30 \mu \mathrm{L}$ of Buffer DK without $20 \%$ glycerol, containing $3 \mu \mathrm{L}$ of NTR complex, 2 mM ATP, 3 $\mathrm{mM} \mathrm{MgCl}{ }_{2}, 1 \mathrm{U} / \mu \mathrm{L}$ RNasin, $50 \mu \mathrm{g} / \mathrm{mL}$ tRNA, at room temperature for $20 \mathrm{~min}$. The mixture was centrifuged and supernatant and pellets were collected for further analysis.

\section{Gradient sedimentation}

Splicing reactions or released intron fractions were subjected to sedimentation analysis on $10 \%-30 \%$ glycerol gradients in a buffer containing $20 \mathrm{mM}$ HEPES ( $\mathrm{pH} 7.9$ ), $100 \mathrm{mM} \mathrm{NaCl}$, and $0.2 \mathrm{mM}$ EDTA. Gradients were centrifuged in SW60 at 50,000 rpm for $3 \mathrm{~h}$ at $4^{\circ} \mathrm{C}$ and collected in $0.25-\mathrm{mL}$ fractions.

\section{Acknowledgments}

We thank W.-Y. Tarn and P. Lin for critical reading of the manuscript and K.J. Deen for English editing. This work was supported by the Academia Sinica and by the National Science Council (Taiwan) NSC92-2321-B-001-017.

\section{References}

Arenas, J.E. and Abelson, J.N. 1997. Prp43: An RNA helicaselike factor involved in spliceosome disassembly. Proc. Natl. Acad. Sci. 94: 11798-11802.

Brody, E. and Abelson, J. 1985. The 'spliceosome': Yeast premessenger RNA associates with a $40 \mathrm{~S}$ complex in a splicingdependent reaction. Science 228: 963-966.

Brow, D.A. 2002. Allosteric cascade of spliceosome activation. Annu. Rev. Genet. 36: 333-360.

Burge, C.B., Tuschl, T.H., and Sharp, P.A. 1999. Splicing of precursors to mRNAs by the spliceosome. In The RNA world, 2nd ed. (eds. R.F. Gesteland et al.), pp. 525-560. Cold Spring Harbor Laboratory Press, Cold Spring Harbor, NY.

Chan, S.-P. and Cheng, S.-C. 2005. The Prp19-associated complex is required for specifying interactions of U5 and U6 with pre-mRNA during spliceosome activation. J. Biol. Chem. 280: 31190-31199.

Chan, S.-P., Kao, D.-I., Tsai, W.-Y., and Cheng, S.-C. 2003. The Prp19p-associated complex in spliceosome activation. Science 302: 279-282.

Chen, H.-R., Jan, S.-P., Tsao, T.Y., Sheu, Y.-J., Banroques, J., and Cheng, S.-C. 1998. Snt309p, a component of the Prp19p-associated complex that interacts with Prp19p and associates with the spliceosome simultaneously with or immediately after dissociation of U4 in the same manner as Prp19p. Mol. Cell. Biol. 18: 2196-2204.

Chen, C.-H., Tsai, W.-Y., Chen, H.-R., Wang, C.-H., and Cheng, S.-C. 2001. Identification and characterization of two novel components of the Prp19p-associated complex, Ntc30p and Ntc20p. J. Biol. Chem. 276: 488-494.

Chen, C.-H., Yu, W.-C., Tsao, T.Y., Wang, L.-Y., Chen, H.-R., Lin, J.-Y., Tsai, W.-Y., and Cheng, S.-C. 2002. Functional and physical interactions between components of the Prp19passociated complex. Nucleic Acids Res. 30: 1029-1037.

Cheng, S.-C. 1994. Formation of the yeast splicing complex A1 and association of the splicing factor PRP19 with the premRNA are independent of the $3^{\prime}$ region of the intron. Nucleic Acids Res. 22: 1548-1554.

Cheng, S.-C. and Abelson, J. 1987. Spliceosome assembly in yeast. Genes \& Dev. 1: 1014-1027.

Cheng, S.-C., Newman, A., Lin, R.-J., McFarland, G.D., and Abelson, J.N. 1990. Preparation and fractionation of yeast splicing extract. Methods Enzymol. 181: 89-96.

Company, M., Arenas, J., and Abelson, J. 1991. Requirement of the RNA helicase-like protein PRP22 for release of messenger RNA from spliceosomes. Nature 349: 487-493.

Fouraux, M.A., Kolkman, M.J., Van der Heijden, A., De Jong, A.S., Van Verooij, W.J., and Pruijn, G.J. 2002. The human La (SS-B) autoantigen interacts with DDX15/hPrp43, a putative 
DEAH-box RNA helicase. RNA 8: 1428-1443.

Frendewey, D. and Keller, W. 1985. Stepwise assembly of a premRNA splicing complex requires U-snRNAs and specific intron sequences. Cell 42: 355-367.

Gavin, A., Bösche, M., Krause, R., Grandi, P., Marzioch, M., Bauer, A., Schultz, J., Rick, J.M., Michon, A., Cruciat, C., et al. 2002. Functional organization of the yeast proteome by systematic analysis of protein complexes. Nature 415: 141147.

Grabowski, P.J., Seiler, S.R., and Sharp, P.A. 1985. A multicomponent complex is involved in the splicing of messenger RNA precursors. Cell 42: 345-353.

Hazbun, T.R., Malmström, L., Anderson, S., Graczyk, B.J., Fox, B., Riffle, M., Sundin, B.A., Aranda, D., McDonald, W.H., Chiu, C.-H., et al. 2003. Assigning function to yeast proteins by integration of technologies. Mol. Cell 12: 1353-1365.

Ito, T., Chiba, T., Ozawa, R., Yoshida, M., Hattori, M., and Sakaki, Y. 2001. A comprehensive two-hybrid analysis to explore the yeast protein interactome. Proc. Natl. Acad. Sci. 98: 4569-4574.

Krogan, N.J., Pang, W.-T., Cagney, G., Robinson, M.D., Haw, R., Zhong, G., Guo, X., Zhang, X., Canadien, V., Richards, C.P., et al. 2004. High-definition macromolecular ccomposition of yeast RNA-processing complexes. Mol. Cell 13: 225-239.

Laggerbauer, B., Achsel, T., and Lührmann, R. 1998. The human U5-200kD DEXH-box protein unwinds U4/U6 RNA duplices in vitro. Proc. Nat1. Acad. Sci. 95: 4188-4192.

Last, R.L., Maddock, J.R., and Woolford, J.L.J. 1987. Evidence for related functions of he RNA genes of Saccharomyces cerevisia. Genetics 117: 619-631.

Makarov, E.M., Makarova, O.V., Urlaub, H., Gentzel, M., Will, C.L., Wilm, M., and Lührmann, R. 2002. Small nuclear ribonucleoprotein remodeling during catalytic activation of the spliceosome. Science 298: 2205-2208.

Martin, A., Schneider, S., and Schwer, B. 2002. Prp43 is an essential RNA-dependent ATPase required for release of lariatintron from the spliceosome. I. Biol. Chem. 277: 1774317750.

Raghunathan, P.L. and Guthrie, C. 1998. A spliceosomal recycling factor that reanneals U4 and U6 snRNPs. Science 279: 857-860.

Roy, J., Kim, K., Maddock, J.R., Anthony, J.G., and Woolford Jr., J.L. 1995. The final stages of spliceosome maturation require Spp2p that can interact with the DEAH box protein Prp2p and promote step 1 of splicing. RNA 1:375-390.

Schwer, B. and Gross, C.H. 1998. Prp22, a DExH-box RNA helicase, plays two distinct roles in yeast pre-mRNA splicing. EMBO J. 17: 2086-2094.

Silverman, E., Edwalds-Gilbert, G., and Lin, R.-J. 2003. DExD/ H-box proteins and their partners: Helping RNA helicases unwind. Gene 312: 1-16.

Silverman, E.J., Maeda, A., Wei, J., Smith, P., Beggs, J.D., and Lin, R.-J. 2004. Interaction between a G-patch protein and a spliceosome DEXD/H-box ATPase that is critical for splicing. Mol. Cell. Biol. 24: 10101-10110.

Staley, J.P. and Guthrie, C. 1998. Mechanical devices of the spliceosome: Motors, clocks, springs, and things. Cell 92: 315-326.

Stevens, S.W., Ryan, D.E., Ge, H.Y., Moore, R.E., Young, M.K., Lee, T.D., and Abelson, J. 2002. Composition and functional characterization of the yeast spliceosomal penta-snRNP. Mol. Cell 8: 31-44.

Tarn, W.-Y., Lee, K.-R., and Cheng, S.-C. 1993a. The yeast PRP19 protein is not tightly associated with small nuclear RNAs, but appears to associate with the spliceosome after binding of U2 to the pre-mRNA and prior to formation of the functional spliceosome. Mol. Cell. Biol. 13: 1883-1891.

- 1993b. Yeast precursor mRNA processing protein PRP19 associates with the spliceosome concomitant with or just after dissociation of U4 small nuclear RNA. Proc. Nat1. Acad. Sci. 90: 10821-10825.

Tarn, W.-Y., Hsu, C.-H., Huang, K.-T., Chen, H.-R., Kao, H.-Y., Lee, K.-R., and Cheng, S.-C. 1994. Functional association of essential splicing factor(s) with PRP19 in a protein complex. EMBO J. 13: 2421-2431.

Tsai, W.-Y., Chow, Y.-T., Chen, H.-R., Huang, K.-T., Hong, R.-I., Jan, S.-P., Kuo, N.-Y., Tsao, T.Y., Chen, C.-H., and Cheng, S.-C. 1999. Cef1p is a component of the Prp19p-asociated complex and essential for pre-mRNA splicing. J. Biol. Chem. 274: 9455-9462.

Will, C.L., Urlauh, H., Achsel, T., Gentzel, M., Wilm, M., and Lührmann, R. 2002. Characterization of novel SF3b and 17S U2 snRNP proteins, including a human Prp5p homologue and an SF3b DEAD-box protein. EMBO I. 21: 4978-4988.

Winston, F., Chumley, F., and Fink, G.R. 1983. Eviction and transplacement of mutant genes in yeast. Methods Enzymol. 101: 211-228.

Zhou, Z., Licklider, L.J., Gygi, S.P., and Reed, R. 2002. Comprehensive proteomic analysis of the human spliceosome. $\mathrm{Na}$ ture 419: 182-185. 


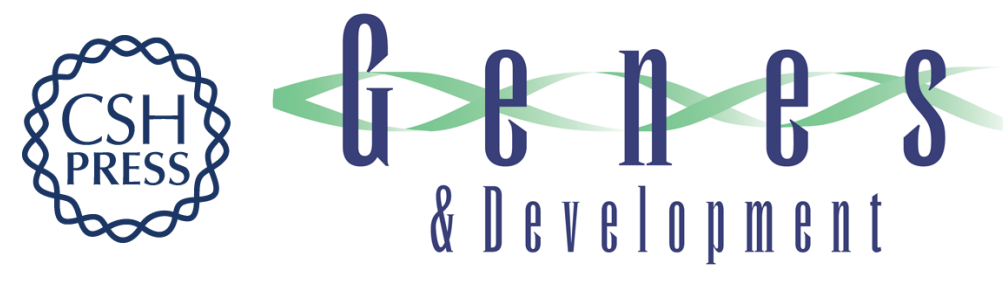

\section{Spliceosome disassembly catalyzed by Prp43 and its associated components Ntr1 and Ntr2}

Rong-Tzong Tsai, Ru-Huei Fu, Fu-Lung Yeh, et al.

Genes Dev. 2005, 19:

Access the most recent version at doi:10.1101/gad.1377405

Supplemental http://genesdev.cshlp.org/content/suppl/2005/11/30/19.24.2991.DC1
Material

References This article cites 37 articles, 21 of which can be accessed free at:

http://genesdev.cshlp.org/content/19/24/2991.full.html\#ref-list-1

License

Email Alerting Receive free email alerts when new articles cite this article - sign up in the box at the top

Service right corner of the article or click here.

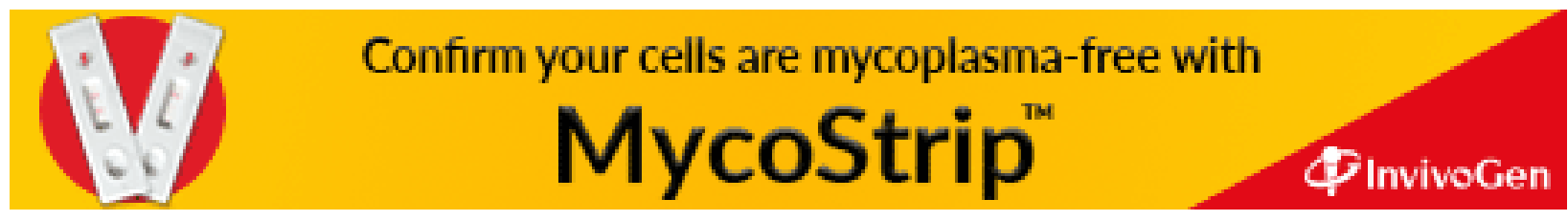

